\title{
Pneumonia among COPD patients using inhaled corticosteroids and long-acting bronchodilators
}

\section{*Douglas Mapel ${ }^{a}$, Michael Schuma , Marianne Yood ${ }^{b}$, Jeffrey Brownc, David Millerd, Kourtney Davis ${ }^{d}$}

a Lovelace Clinic Foundation, Albuquerque, New Mexico, USA

b Department of Epidemiology \& Public Health, Yale University School of Medicine, Hamden, Connecticut, USA

Harvard Pilgrim Health Care, Harvard Medical School, Boston, Massachusetts, USA

d GlaxoSmithKline, Research Triangle Park, North Carolina, USA

Received 18th May 2009; revised 28th September 2009; accepted 21st October 2009; online 15th January 2010

\begin{abstract}
Aim: To assess the risk of pneumonia among COPD patients using salmeterol/fluticasone propionate combination inhalers (SFC), inhaled corticosteroids (ICS), or long-acting beta-agonists (LABA), alone or in combination, compared to those using only short-acting bronchodilators (SABD).

Method: The study population comprised 5245 individuals using inhaled treatment for COPD, identified from the databases of three large regional managed care organisations from different parts of the USA. Longitudinally-collected administrative data were obtained on their clinical histories and treatments. Nested case-control methods were used to calculate adjusted odds ratios (OR) for the risk of pneumonia while on therapy.

Results: 2154 patients had at least one diagnosed case of pneumonia between 1st September 2001 and 31st August 2003. Relative to $\mathrm{SABD}$, the only treatment associated with a non-significant increased risk of pneumonia was ICS used alone $(\mathrm{OR}=1.29 ; 95 \% \mathrm{Cl}$ : 0.96-1.73; $\mathrm{p}=0.09$ ). Users of $\mathrm{LABA}$ alone $(\mathrm{OR}=0.92 ; 95 \% \mathrm{Cl}: 0.69-1.22)$ or $S F C(\mathrm{OR}=1.03 ; 95 \% \mathrm{Cl}$ : $0.74-1.42)$ had no increased risk for pneumonia relative to SABD. Advanced age and severity of lung disease were strongly associated with increased risk for pneumonia.

Conclusion: Treatment with ICS or an ICS/LABA combination inhaler was not associated with a significantly increased risk of developing pneumonia.

C 2010 Primary Care Respiratory Society UK. All rights reserved.

D Mapel et al. Prim Care Resp J 2010; 19(2): 109-117

doi:10.4104/pcrj.2009.00072
\end{abstract}

Keywords COPD, pneumonia, corticosteroids, beta-agonists

\section{Introduction}

International guidelines for chronic obstructive pulmonary disease (COPD) management recommend long-acting bronchodilators (e.g., $\beta_{2}$-agonists such as salmeterol or formoterol, and anti-cholinergics such as tiotropium) as firstline pharmacologic treatment for COPD patients who have airflow obstruction and persistent daily symptoms. ${ }^{1-3}$ Current guidelines also recommend inhaled corticosteroids (ICS) for patients with severe airflow obstruction (forced expiratory volume in 1 second ( $\left.\mathrm{FEV}_{1}\right)$ less than $50 \%$ of predicted) and acute exacerbations of respiratory symptoms that require treatment with oral steroids or antibiotics. The use of ICS in COPD has long been a controversial topic, ${ }^{4,5}$ however, several randomised controlled trials (RCTs) have demonstrated that ICS are effective in improving baseline lung function, reducing chronic symptoms, and maintaining quality of life among COPD patients who have severe airflow obstruction and chronic bronchitis symptoms. ${ }^{6-12}$

The TORCH (Towards a Revolution in COPD Health) study was an RCT designed to compare the efficacy of twice-daily treatment with a combined fluticasone propionate $500 \mathrm{mcg} / \mathrm{salmeterol} 50 \mathrm{mcg}$ inhaler (SFC), a fluticasone

\footnotetext{
* Corresponding author: Dr Douglas W Mapel, Lovelace Clinic Foundation, 2309 Renard PI SE, Suite 103, Albuquerque, New Mexico, 87106 United States. Tel: 505-938-9900 Fax: 505-938-9940 E-mail: dmapel@comcast.net
} 
propionate $500 \mathrm{mcg}$ inhaler, or a salmeterol $50 \mathrm{mcg}$ inhaler, versus placebo, with survival as the primary endpoint. ${ }^{13}$ Shortacting inhaled bronchodilators were permitted in all four study treatment groups. After three years, those using SFC had a $17 \%$ reduction in all-cause mortality as compared to the placebo group $(p=0.052)$. However, a small but significantly increased incidence of pneumonia adverse event reports was noted in both the SFC and fluticasone propionate-alone groups, as compared to placebo (19.6\%, $18.3 \%$, and $12.3 \%$, respectively; $p<0.001)$. The increased risk was evident at one year into the study; however, the risk of death due to pneumonia was not increased. The recently published INSPIRE study compared SFC to inhaled tiotropium over two years with a primary end point of exacerbations, and also found a higher incidence of pneumonia adverse event reporting with SFC (8\% vs. $4 \% ; p<0.01) .{ }^{14}$ Another recent RCT that compared SFC to inhaled salmeterol over 44 weeks with a primary endpoint of COPD exacerbation again found a higher incidence of pneumonia reports in the SFC group $(4.5 \%$ vs. $1.8 \%)$, although the statistical significance was not reported. ${ }^{15}$ Pneumonia was not reported as an adverse outcome in 13 other RCTs of ICS in COPD. ${ }^{16}$ Nevertheless, the findings of these more recent studies have raised concerns about the possible association between ICS use and the risk of pneumonia in COPD.

The aim of this study was to see whether ICS treatment, with or without a long-acting $\beta$ agonist (LABA), is associated with an increased risk of a diagnosis of pneumonia among COPD patients treated in the general population. To accomplish this, we identified COPD patients enrolled in one of three large regional managed care organisations from different parts of the United States, and captured their clinical histories and treatments using longitudinally-collected administrative data. We then examined the risk factors for pneumonia and the associations between pneumonia and different respiratory treatments using nested case-control analyses.

\section{Methods}

\section{Data sources}

COPD patients for this study were identified from three managed care programs that participate in the HMO Research Network, a program funded by the National Institutes of Health for the purpose of facilitating health services and quality improvement research (www.hmoresearchnetwork. org). A similar cohort was recently used to describe the effects of ICS with and without LABA on survival in COPD. ${ }^{17}$ Information about demographic factors, diagnoses, and dates of service were collected from administrative data routinely collected from clinical billing records. Information about treatment with specific medications was captured from prescription drug fills contained in pharmacy records.

The Lovelace Clinic Foundation was the project's coordinating centre and the centre affiliated with the Lovelace Health Plan, which is a staff and network model managed care provider based in Albuquerque, New Mexico. The Lovelace Health Plan had approximately 140,000 adult members in 2001, which included participants in their Medicare, Medicaid, and over 700 employer-sponsored programs.

The two collaborating centres were the Center for Health Services Research and the Channing Laboratory. The Center for Health Services Research at the Henry Ford Health Systems is based in Detroit, Michigan, and is affiliated with Henry Ford's Health Alliance Plan. This is a primarily staff-model managed care system serving over 600,000 members in the metropolitan Detroit area. The Channing Laboratory is affiliated with Harvard Pilgrim Health Care, which is a staff and network system that provides access to almost all physicians in Massachusetts. The Institutional Review Boards at all three centres reviewed and approved this project.

\section{Study population}

COPD patients were identified using the ICD-9 diagnosis codes included in the administrative data. Patients were required to be continuously enrolled in their health plan from 1st September 2000 until 31st August 2001, which defines the study's baseline year. The full study period was 1st September 2000 to 31st August 2003. The inclusion criteria included:

(1) all persons who had one inpatient visit or two outpatient visits on separate days with an ICD-9 code consistent with COPD (491.x [chronic bronchitis], 492.x [emphysema], or 496 [chronic airway obstruction]) during the baseline year;

(2) all study subjects were required to have been dispensed at least one of the respiratory drugs (short-acting bronchodilator, long-acting bronchodilator, or inhaled corticosteroids) used to treat COPD at any time during the study period.

Patients with other chronic lung diseases not typically included in the classification of COPD, such as coal workers pneumoconiosis or idiopathic pulmonary fibrosis, were excluded.

For the three sites pooled we identified 5438 individuals who met the COPD inclusion criteria.

\section{Pneumonia definitions}

Pneumonia cases were defined as patients with any pneumonia-related ICD diagnosis code (ICD-9 codes 480.0 through 487.0) in an outpatient, emergency room, or inpatient setting. Diagnoses made in an emergency room or outpatient clinic were also required to have a chest $\mathrm{x}$-ray, which excluded 193 patients from the original cohort. We identified 2154 individuals with at least one pneumonia event 
during the study period, 2222 of whom were diagnosed in an inpatient setting. From this cohort of 2154 patients, 1478 developed pneumonia on or after 1st September 2001.

Demographic factors, co-morbidities, and healthcare utilisation

Using the database, we captured clinical factors that were likely to affect the risk of developing pneumonia, such as comorbid conditions, demographic factors, and healthcare utilisation that are associated with more severe COPD. These factors included age, gender, asthma diagnosis, CharlsonDeyo co-morbidity score, COPD hospitalisations, the number of emergency department visits for COPD, the number of outpatient encounters for COPD, and oral corticosteroid use. Co-morbidities were identified during the baseline year and were defined as the presence of at least one ICD-9 code. Asthma was defined as at least one inpatient or two outpatient ICD-9 codes for 493.x to help reduce the risk of COPD/asthma misclassification. The Charlson-Deyo scores were calculated using only outpatient data. ${ }^{18}$ Spirometry data were not included in any of the administrative databases and was not available for this analysis.

The National Drug Codes (NDC) were used to abstract respiratory drug utilisation from the managed care databases. For consistency we assumed that dispensing of one inhaler canister equaled one month of treatment. The lists of dispensed medications were reviewed for errors or missing data by the primary investigator, and any entries that could not be associated with a specific product or a specific quantity of medication were excluded.

\section{Statistical methods}

To provide a comparison of the risk of pneumonia while continuously exposed to different respiratory medications, we used the SAS LIFETEST actuarial life table method (similar to the Kaplan-Meier method but using interval grouped data) to create pneumonia incidence plots. This analysis was based on the 5438 COPD patients who met the original inclusion and exclusion criteria, less the 193 persons who had an outpatient diagnosis of pneumonia but no confirming chest $x$-ray. We restricted the analysis to patients who were continuously compliant with their respiratory treatment (SFC, ICS only, LABA only, or SABD alone) and did not cross over to a different medication to support the plausibility of a temporal exposure-disease association. Day 0 was the first day of prescription of a new respiratory medication, and patients were censored if they developed pneumonia, died, stopped taking the medication, or reached the end of the study period without pneumonia. Patients were considered to have stopped treatment if there was more than a 45-day gap in prescription dispensing. Patients had to have a prescription dispensed within 30 days of the next treatment period to be included at the start of the next interval. We used the SAS
LIFETEST procedure to test the homogeneity of survival curves over time by treatment groups.

The benefit of the nested case-control approach is that it helps to resolve problems of potential misclassification of exposure in the time period prior to the incident pneumonia event date. This extension of the retrospective cohort analysis uses data from pneumonia cases and their closely matched controls, both of whom are "nested" within the COPD study cohort. ${ }^{19}$ Cohort entry time was defined as the first COPD diagnosis. Cohort exit time or censoring was defined as the date of first pneumonia diagnosis after the baseline year or the end of the study observation period.

Cases were defined as persons who had a pneumonia event after 1st September 2001 (the end of the baseline year). The first day of a pneumonia diagnosis is defined as the case date. Many individuals (cases and controls) also had a pneumonia event in the baseline year (1st September 2000 31st August 2001). We adjusted for this increased risk of pneumonia in the analysis by including a "prior pneumonia" covariate in the logistic regression models.

Controls were randomly selected from the matched risk set for each case. Controls are defined based on a risk set that consists of all non-cases in the nested cohort at risk of becoming a case at the time a patient with pneumonia becomes a case. In this definition, a person who becomes a case at a later date is eligible to be a control for other cases at person-time prior to the pneumonia event date. This also allows for a control to be matched to more than one case. The matching criteria were:

1) date of COPD diagnosis for the case \pm 30 days (same entry point);

2) age \pm 1 year; and

3) gender.

Controls were selected using a SAS algorithm that allows for sampling with replacement of controls (controls can be matched to more than one case), and that allows for a case to be a control if it is in the risk set for a case with an earlier case date..$^{20}$ We used a 1:4 matching (one case and up to four controls per case).

The nested case-control analysis was adjusted by the following clinical covariates: asthma diagnosis, CharlsonDeyo comorbidity index, COPD hospitalisations, the number of emergency department visits for COPD, the number of outpatient encounters for COPD, oral corticosteroid use, prior pneumonia, and treatment site. The covariates for COPD severity (inpatient admissions, outpatient encounters and emergency room encounters), as well as oral corticosteroid use, were defined based on the 12-month period prior to the case date. The COPD covariates were coded as categorical variables prior to analysis. Number of outpatient encounters were grouped into 0-2 (reference group), 3-4, 5-12 and 13+ 
visits, which was the quartile distribution. Emergency room visits and inpatient admissions were coded as either no encounters (reference group) or at least 1 visit/admission in the year prior to the case date. Oral corticosteroid use and prior pneumonia were coded as yes/no (no = reference group).

The following treatment categories were identified: SFC, ICS with LABA, ICS without LABA, LABA without ICS, no treatment, and $S A B D$. These categories were mutually exclusive. There were 24 patients who received SFC and ICS or LABA in the 90 days prior to pneumonia who were set aside due to insufficient numbers. Those who received ICS with LABA did not necessarily receive them on the same dates, but they were dispensed in the same time window. Additional analyses were run that stratified the SFC group by product strength (100/50, 250/50, 500/50).

We extracted the pharmacy utilisation data for the time period from case date to 90 days prior to the case date. Individuals (cases and controls separately) were then classified into the treatment groups listed above based on only those exposure categories considering the 90-day window prior to pneumonia event date for cases or matched date for controls at risk. We also conducted the analysis evaluating exposure to treatments received in longer prior periods of 180-days and 365-days.

\section{Results}

Among the 5438 COPD patients included in the study cohort, age was an important risk factor for pneumonia (see table 1). Approximately $43 \%$ of persons age 73 years and older had at least one diagnosis of pneumonia during the study period, and their pneumonia diagnosis rate per year was almost twice that of COPD patients aged 40 to 56 years. The pneumonia diagnosis rate among men (24 cases per 100 person-years) was slightly higher than that among women (21 cases per 100 person-years), but the difference did not reach statistical significance. Women comprised $53.7 \%$ of the total cohort.

\section{Table 1. Pneumonia incidence rates by age group.}

\begin{tabular}{lccc}
$\begin{array}{l}\text { Age } \\
\text { group }\end{array}$ & Total & $\begin{array}{c}\text { Persons } \\
\text { with } \geq 1 \\
\text { pneumonias }\end{array}$ & $\begin{array}{c}\text { Pneumonia } \\
\text { rate per 100 } \\
\text { person-Years }\end{array}$ \\
\hline $40-56$ & 940 & $237(25.2 \%)$ & 15.4 \\
\hline $57-65$ & 1247 & $370(29.7 \%)$ & $18.8^{*}$ \\
\hline $66-72$ & 1265 & $453(35.8 \%)$ & $22.3 * *$ \\
\hline $73+$ & 1793 & $776(43.3 \%)$ & $28.9 * *$ \\
\hline Total & 5245 & $1836(35.0 \%)$ & 22.4 \\
\hline *P value 0.02 for chi-square comparison with 40-56 age group. \\
**P value $<0.01$ for chi-square comparison with preceding age group.
\end{tabular}

The unadjusted Kaplan-Meier type survivorship plot of pneumonia incidence among those who were continuously compliant with treatment illustrates that those who were either on SFC or LABA alone had a lower risk of pneumonia diagnosis than those on ICS or SABD only $(p=0.002$ and 0.003 by log rank and Wilcoxon tests, respectively) (Figure 1). Of the 2154 pneumonia events identified during the baseline and follow-up periods, $35 \%$ occurred within 60 days of the first prescription dispensing for a respiratory medication, which suggests that a large proportion of patients are experiencing clinical deterioration, or are otherwise not felt to be optimally managed, just prior to a diagnosis of pneumonia being made. Compliance with all treatment regimens was very poor. In a 6-month treatment period, patients using SFC had a higher percentage with continuous treatment than those in the SABD only group $(29.8 \%$ vs. $12.8 \%$; $p<0.01)$.

The baseline characteristics of the pneumonia cases are described in Table $2 A$, and those of the age- and gendermatched controls are described in Table 2B. All but four of the 1478 pneumonia cases from the follow-up period were matched to at least one control. Among both cases and controls, patients treated with SFC, LABA alone, or the combination of an ICS and LABA tended to be younger than those who had an ICS alone, just a SABD, or no treatment. -Treatments did not differ significantly by gender. Pneumonia cases tended to have more severe lung disease, as evidenced by the higher number of outpatient visits, emergency department visits, or hospitalisations for COPD during the baseline period. Persons who did not have respiratory medication dispensed (no treatment) tended to have less severe lung disease than those in any of treatment groups. Cases were significantly more likely to have a Charlson-Deyo score of $\geq 1$, indicating a higher prevalence of significant comorbidities $(p<0.01)$. Cases and controls treated with any

Figure 1. Survivorship plot.

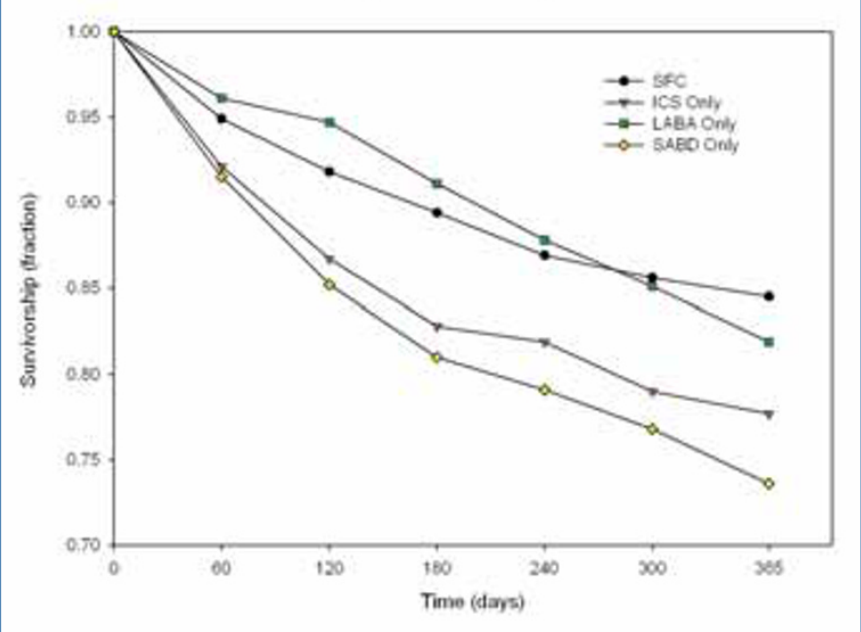


Table 2a. Baseline characteristics of pneumonia cases according to treatment group. Status $\mathbf{9 0}$ days prior to pneumonia case date.

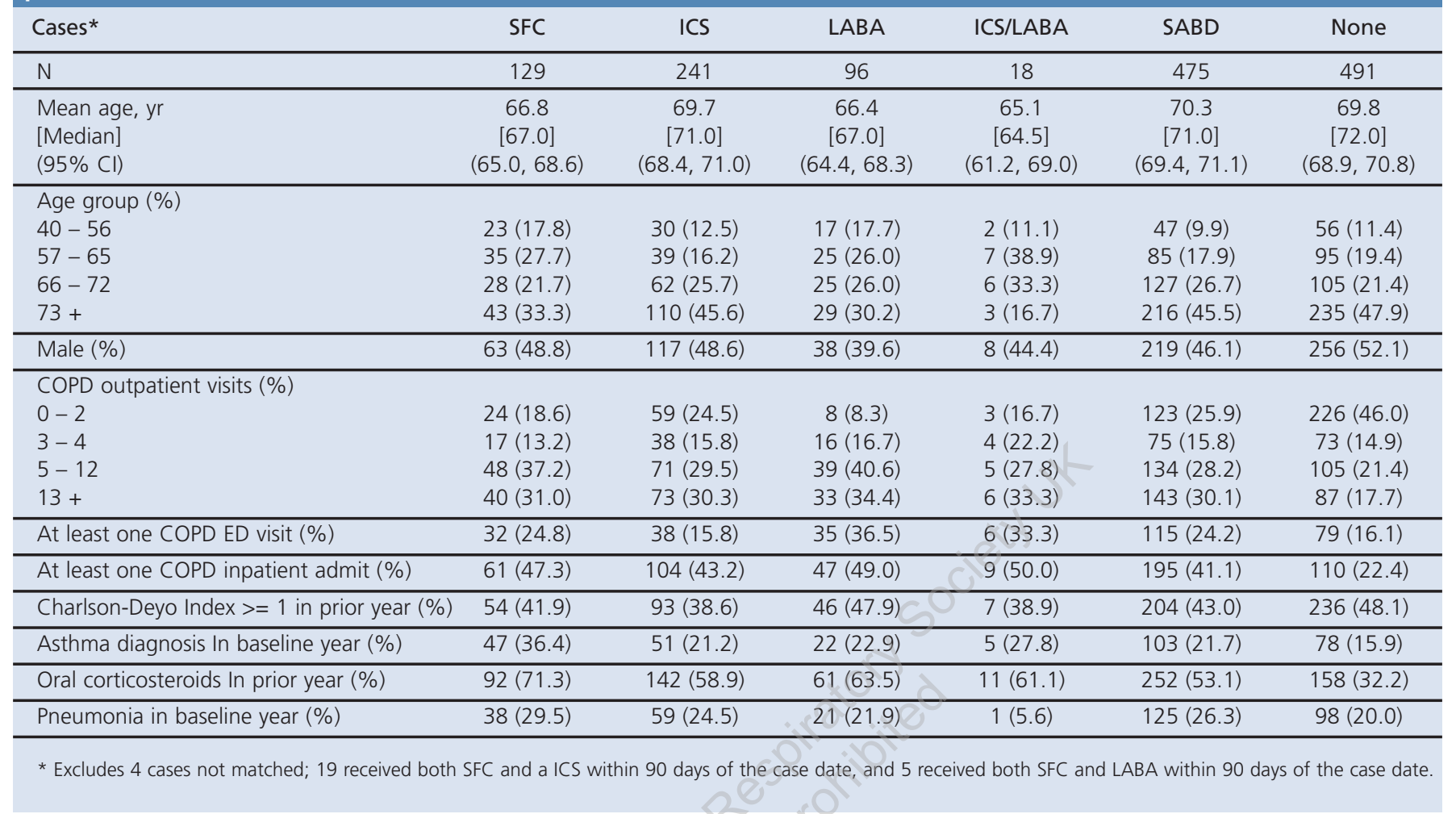

Table $\mathbf{2 b}$. Baseline characteristics of controls according to treatment group. Status 90 days prior to matched pneumonia case date.

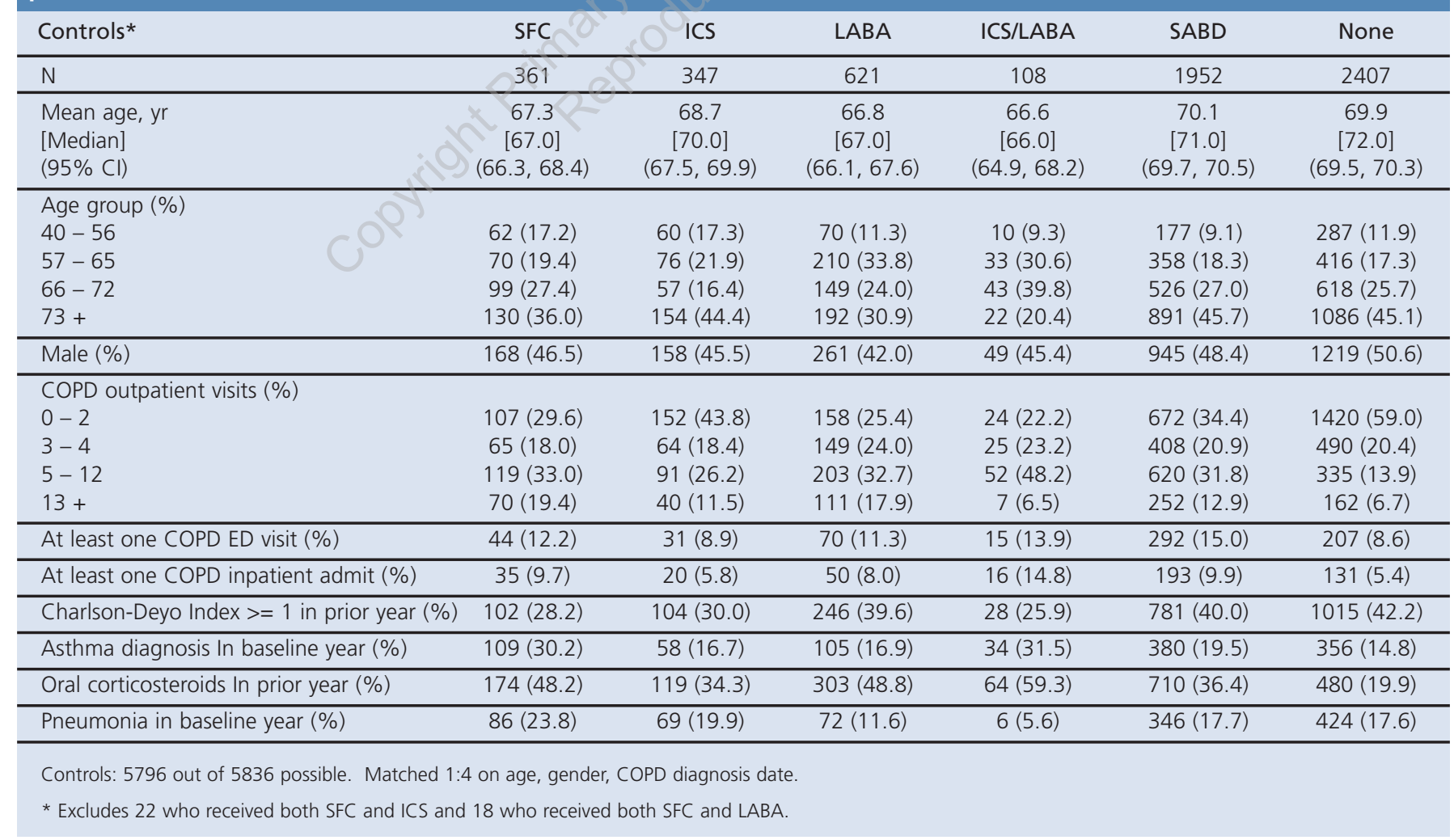


D Mapel et al.

Table 3. Adjusted risk of pneumonia from logistic regression - nested case-control analysis.

\begin{tabular}{|c|c|c|c|c|c|c|c|c|c|}
\hline \multirow[b]{2}{*}{ Variable } & \multicolumn{3}{|c|}{ 90-days prior to case date } & \multicolumn{3}{|c|}{180 -days prior to case date } & \multicolumn{3}{|c|}{ 365-days prior to case date } \\
\hline & $\begin{array}{l}\text { Odds } \\
\text { Ratio }\end{array}$ & $\begin{array}{l}95 \% \\
\mathrm{LCL}\end{array}$ & $\begin{array}{l}95 \% \\
\text { UCL }\end{array}$ & $\begin{array}{l}\text { Odds } \\
\text { Ratio }\end{array}$ & $\begin{array}{c}95 \% \\
\text { LCL }\end{array}$ & $\begin{array}{l}95 \% \\
\text { UCL }\end{array}$ & $\begin{array}{l}\text { Odds } \\
\text { Ratio }\end{array}$ & $\begin{array}{r}95 \% \\
\mathrm{LCL}\end{array}$ & $\begin{array}{r}95 \% \\
\text { UCL }\end{array}$ \\
\hline SABD (reference) & 1.0 & & & 1.0 & & & 1.0 & & \\
\hline SFC & 1.03 & 0.74 & 1.42 & 0.97 & 0.71 & 1.34 & 0.82 & 0.58 & 1.15 \\
\hline ICS with LABA & 0.58 & 0.30 & 1.12 & $0.57^{*}$ & 0.34 & 0.95 & $0.65^{*}$ & 0.43 & 0.98 \\
\hline ICS without LABA & 1.29 & 0.96 & 1.73 & 1.28 & 0.98 & 1.67 & 1.26 & 0.99 & 1.59 \\
\hline LABA without ICS & 0.92 & 0.69 & 1.22 & 0.97 & 0.73 & 1.27 & 0.89 & 0.68 & 1.16 \\
\hline No respiratory meds. & 1.07 & 0.88 & 1.30 & 1.02 & 0.83 & 1.25 & 1.01 & 0.79 & 1.30 \\
\hline$\leq 2$ COPD outpatient encounters (ref.) & 1.0 & & & 1.0 & & & 1.0 & & \\
\hline 3-4 COPD outpatient encounters & 1.07 & 0.85 & 1.34 & 1.06 & 0.85 & 1.34 & 1.05 & 0.84 & 1.32 \\
\hline 5-12 COPD outpatient encounters & $1.51 *$ & 1.21 & 1.89 & $1.50 *$ & 1.20 & 1.86 & 1.51 * & 1.21 & 1.88 \\
\hline 13+ COPD outpatient encounters & $1.59 *$ & 1.22 & 2.06 & $1.57^{\star}$ & 1.21 & 2.03 & $1.59 *$ & 1.22 & 2.06 \\
\hline No emergency dept. encounters (ref.) & 1.0 & & & 1.0 & & & 1.0 & & \\
\hline$\geq 1$ emergency dept. encounter & $1.92 *$ & 1.56 & 2.36 & $1.94^{*}$ & 1.58 & 2.39 & $1.93^{*}$ & 1.57 & 2.37 \\
\hline No COPD hospitalizations (ref.) & 1.0 & & & 1.0 & C) & & 1.0 & & \\
\hline$\geq 1$ COPD hospitalization & $2.83^{*}$ & 2.30 & 3.48 & $2.84^{*}$ & 2.31 & 3.49 & $2.88^{*}$ & 2.34 & 3.54 \\
\hline Charlson-Deyo score 0 (reference) & 1.0 & & & 1.0 & & & 1.0 & & \\
\hline Charlson-Deyo score $\geq 1$ & 1.03 & 0.88 & 1.22 & 1.04 & 0.88 & 1.22 & 1.03 & 0.88 & 1.21 \\
\hline No asthma during baseline year (ref.) & 1.0 & & & 1.0 & & & 1.0 & & \\
\hline Asthma during baseline year & 0.95 & 0.77 & 1.17 & 0.97 & 0.79 & 1.2 & 0.97 & 0.79 & 1.19 \\
\hline No oral steroid use (reference) & 1.0 & & & 1.0 & & & 1.0 & & \\
\hline Oral steroid use & $1.41 *$ & 1.18 & & $1.39^{*}$ & 1.17 & 1.66 & $1.41 *$ & 1.18 & 1.68 \\
\hline No pneumonia in baseline year (ref.) & 1.0 & & & 1.0 & & & 1.0 & & \\
\hline Pneumonia in baseline year & 1.08 & 0.89 & 1.32 & 1.08 & 0.89 & 1.32 & 1.08 & 0.89 & 1.32 \\
\hline
\end{tabular}

form of ICS were more likely to have an asthma diagnosis in addition to their COPD diagnosis, and they were also more likely to be treated with oral corticosteroids.

The results of the nested case-control analyses using the SABD group as the reference group are presented in Table 3 . The analysis was run using 3-month, 6-month, and 12-month treatment windows prior to the pneumonia date to examine what effect the accrual period had on the treatment effect estimates. Factors that were significantly associated with an increased risk for pneumonia diagnosis included the indicators of more severe lung disease, such as five or more outpatient encounters, an emergency department visit, a hospitalisation, or use of oral corticosteroids during the baseline year. The only treatment reaching statistical significance is the ICS and LABA combination group, which showed a reduced risk of pneumonia diagnosis for the 180-day and 365-day exposure windows, but not for the 90-day exposure window. However, the ICS \& LABA combined group had very small sample size and the resulting risk estimates lack precision. Those using ICS alone tended to have an increased risk of pneumonia diagnosis (OR 1.26 - 1.29) that did not quite reach statistical significance.

The odds ratio estimate for the various treatments did not change substantially when the treatment groups were compared to persons who had no treatment as the reference group (Figure 2). An additional analysis was run that stratified SFC by the dose of fluticasone propionate to see if those taking higher amounts were at higher risk for pneumonia. Those using the $500 / 50 \mathrm{mcg}$ formulation were no more likely to have a diagnosis of pneumonia (OR $0.96 ; 95 \% \mathrm{Cl} 0.63$ 1.49) than those using the $250 / 50 \mathrm{mcg}(1.23 ; 0.81-1.88)$ or the $100 / 50 \mathrm{mcg}(1.26 ; 0.58-2.72)$ formulations, as compared to the SABD reference group (Data not shown).

To test the sensitivity of the treatment effects to the disease severity factors and other factors in the model, we explored a variety of models in which we removed one or more of the various covariates. Reducing the model covariate set had almost no effect on the relative risks for the treatment 


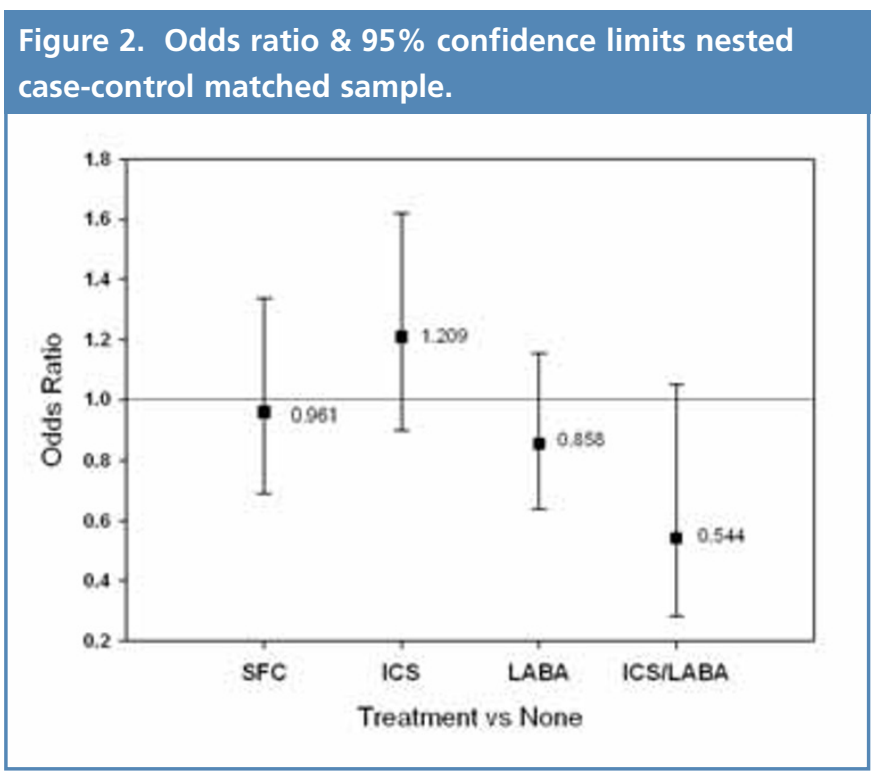

groups, suggesting that these covariates are independent risk factors from treatment effects.

\section{Discussion}

In our population-based historical cohort, COPD patients using ICS alone had a slightly increased risk of a diagnosis of pneumonia that did not reach statistical significance (adjusted risk 26 to 29\%). Those who used SFC or other combinations of ICS with LABA did not have an increased risk for pneumonia diagnosis. Using COPD patients on only SABD or patients not using any respiratory medications as control groups did not affect these results.

Pneumonia was a very commonly reported complication among COPD patients, with an average of 22.4 events for each 100 patient-years of follow-up. Age was a strong clinical risk factor, with COPD patients age 73 and older having an unadjusted rate of confirmed pneumonia $88 \%$ greater than that of persons age 40 to 54 . More severe disease, as indicated by oral corticosteroid use or by emergency department visits, hospitalisations, or increased outpatient encounters for COPD in the baseline year of the study, also doubled or tripled the risk for pneumonia. According to the nested case-control analysis, the risks for pneumonia imparted by inhaled corticosteroids, if any, are small compared to the risks associated with advanced age or more severe lung disease.

Population-based studies have shown that the risk factors for community-acquired pneumonia among adults in the general population include chronic lung disease, heart disease, alcoholism, immunosuppressive therapy, poor oral hygiene, increased outdoor air pollution, and advanced age. $^{21-27}$ Active cigarette smoking increases the risk for pneumonia among both COPD and non-COPD patients. ${ }^{28}$
There is little published information specifically about risk factors for pneumonia among COPD patients. In a study by Soriano et al. of comorbidities among incident COPD cases treated in primary care clinics in the UK, ${ }^{29}$ the relative risk for pneumonia among COPD patients was 16 times that of ageand gender-matched controls (95\% Cl: $8.7-29.3)$. This study did not calculate risk estimates for additional factors associated with pneumonia in COPD, other than noting that the relative risk for pneumonia and other infections in COPD was even higher among persons over age 65. In an analysis of participants in the Copenhagen City Heart Study, increased severity of COPD as assessed by GOLD staging was associated with an increased risk for hospitalisation for lower respiratory tract infection, with those having severe to very severe COPD having a relative risk of $3.3(95 \% \mathrm{Cl}: 2.6-4.1)$ as compared to those with normal lung function. ${ }^{30}$

One of the main limitations of using historical cohorts to examine disease/treatment associations is the potential for bias by indication. We found that approximately one-third of pneumonia events were diagnosed within 60 days after a new prescription for a respiratory drug was dispensed. These data indicate a large potential for bias by indication, whereby patients who are unstable episodically increase their medication use and treatment-seeking behavior just before the pneumonia diagnosis is made. It is possible in the nested case-control approach to adjust for differences in lung disease severity just prior to the pneumonia event, but this is difficult to do completely using automated claims data. We have used several clinical utilisation factors that are reasonable indicators of more severe COPD - such as oral corticosteroid use and hospitalisations for COPD - and our analyses suggest that these factors did not substantially confound the treatment effect risk estimates. Nevertheless, it is simply not possible in a retrospective study of automated data to eliminate fully the possibility that associations between a treatment indicated for more severe patients and outcome simply reflect the fact that patients who are unstable are more likely to seek treatment.

Another of the major limitations of a pharmacoepidemiology study in an historical cohort is poor compliance with treatment. It is very difficult to establish a causal association between a treatment and an outcome when patients only sporadically take their medicines. One can simply eliminate persons who stop refilling their treatment, as we did in our Kaplan-Meier type analysis, but then selection biases inevitably are introduced. Intent to treat analyses such as the Cox proportional hazard (CPH) model can help to adjust for these selection biases, but still require stringent criteria for compliance to help establish the treatment-disease association. Some have suggested using $\mathrm{CPH}$ models with time-dependent covariates as a way of adjusting for changes in compliance; however, valid time-dependent analyses 
require that the changes in treatments be independent of changes in clinical condition, and we have already established that this is not the case in COPD. The main benefit of the nested case-control approach is that it assesses exposure to medications dispensed in the time period just prior to developing pneumonia, increasing the probability of a temporal exposure/disease association. We explored the potential bias of misclassification of exposure in the nestedcase control analysis by varying the exposure window from dispensing of medication within 90 days to 180 or 365 days. The treatment effect estimates did not change substantially by varying the exposure window, suggesting that any potential misclassification caused by variability in exposure prior to the pneumonia event was negligible. Confounding by indication is still possible due to inadequate adjustment for the differences in disease severity. However, the treatment effect estimates were not changed when patients without respiratory treatment, a population that had substantially fewer hospitalisations and other utilisation for COPD, were used as the reference group (data not shown).

There are several possible explanations for the discrepancy between our findings and those of the recent RCTs that found an increased risk of pneumonia reports among COPD patients using SFC or ICS. The limitations of the RCT study design should be considered. Although RCTs are considered the 'gold standard' when it comes to proving treatment efficacy, biases can enter into RCT results when there is differential follow-up by treatment, e.g. when patients in the placebo arm are substantially more likely to drop out. This was observed in both the TORCH study and the earlier ISOLDE study. ${ }^{31}$ In the later years of a long-term RCT, pneumonia reports and other adverse events occurring in the placebo arm may be less likely to be captured simply because fewer placebo patients continue to participate in the study. Another limitation is the lack of specific criteria for diagnosing pneumonia in the RCTs. Pneumonia events were identified during routine study follow-ups, not as they occurred, and radiographic confirmation or other objective measures were not required, which may introduce recall biases. The lack of diagnostic criteria is also a problem due to the overlap between pneumonia and COPD exacerbation, which could lead to potential misclassification. It is notable that the incidence of pneumonia was much lower in the RCTs (approximately 19\% over three years at the highest) than in our population-based cohort (approximately 35\% over three years). Although the TORCH study inclusion criteria were intended to capture a large population of patients with severe COPD, it appears that our population-based cohort was on average more complicated. Thus, the COPD patient populations participating in RCTs may not fully generalise the experience of patients managed in the general population.
Differences in treatment compliance between patients in the general population and those participating in RCTs could also explain some of the discrepancy in our results. A small increase in risk of pneumonia associated with ICS use in the general population might be very difficult to detect since only a minority of those prescribed respiratory medications are consistent users.

Our results are somewhat similar to those of a recent study of hospitalisations for pneumonia among COPD patients who used ICS, although our conclusions are different. ${ }^{32}$ In a nested case-control study of a cohort of COPD patients treated in Quebec, Canada, the adjusted rate ratio of hospitalisation for pneumonia was 1.70 (95\% Cl $1.63-1.77)$ for current ICS users (in the last 60 days preceding the event) compared to non-ICS users in the year prior to the event. The overall risk for pneumonia hospitalisation during the study period (1988-2003) was 1.9 cases per 100 person-years of follow-up, which was similar to the rate of hospitalised pneumonias in our cohort. This group also found a doseresponse relationship, which was not replicated in our analysis. Comparisons between the Canadian study and ours are limited because our analysis included all pneumonia cases confirmed by chest $x$-ray, not just hospitalised pneumonia events. There were also differences in the studies with respect to COPD patient identification and analysis. Ernst et al. identified patients based on respiratory medication use and absence of an inpatient asthma diagnosis, and adjusted for COPD severity based on medication use and prior hospitalisation for COPD. ${ }^{32}$ Our study required a COPD diagnosis according to validated codes and adjusted for COPD severity according to a longer list of variables, which were reported in prior observational studies.

In conclusion, treatment with ICS or combination treatment with ICS/LABA was not associated with a substantially increased risk of diagnosed pneumonia among COPD patients treated in the general population. Any risk that might be attributed to ICS exposure appears to be very small in comparison to the pneumonia risk associated with older age or advanced lung disease. The incidence of pneumonia was remarkably high among COPD patients in this population-based cohort, with or without inhaled treatments. Clinicians need to be cognizant of the proven benefits of treatment - improved lung function along with reduced chronic symptoms and acute exacerbations - in addition to the potential for side effects, and consider this balance in the context of COPD natural history.

\section{Conflict of interest}

Drs. Mapel, Schum, Yood, and Brown were provided a grant from GlaxoSmithKline to conduct this project. Dr. Mapel has conducted other COPD research projects for GlaxoSmithKline, Pfizer Pharmaceuticals, and Boehringer-Ingelheim, and he has served as a consultant to and speaker for each these companies. Drs. Miller and Davis are employees of GlaxoSmithKline. 


\section{References}

1. Celli BR, MacNee W, Agusti A, et al. Standards for the diagnosis and treatment of patients with COPD: a summary of the ATS/ERS position paper. Eur Respir J 2004;23:932-46. http://dx.doi.org/10.1183/09031936.04.00014304

2. Rabe KF, Hurd S, Anzueto A, et al. Global strategy for the diagnosis, management, and prevention of COPD - 2006 update. Am J Respir Crit Care Med 2007;176:532-55. http://dx.doi.org/10.1164/rccm.200703-456SO

3. The GOLD Scientific Committee. Global Strategy for the Diagnosis, Management, and Prevention of COPD, 2007 Update. Accessed at URL: www.GOLDCOPD.com.

4. Calverley PMA. Inhaled corticosteroids are beneficial in chronic obstructive pulmonary disease. Am J Respir Crit Care Med 2000;161:341-2.

5. Barnes PJ. Inhaled corticosteroids are not beneficial in chronic obstructive pulmonary disease. Am J Respir Crit Care Med 2000;161:342-4.

6. Sin DD, McAlister FA, Man SF, Anthonisen NR. Contemporary management of chronic obstructive pulmonary disease: scientific review. JAMA 2003;290:2301-12. http://dx.doi.org/10.1001/jama.290.17.2301

7. Burge PS, Calverley PM, Jones PW, Spencer S, Anderson JA, Maslen TK. Randomized, double blind, placebo controlled study of fluticasone propionate in patients with moderate to severe chronic obstructive pulmonary disease: the ISOLDE trial. BMJ 2000;320:1297-303. http://dx.doi.org/10.1136/ bmj.320.7245.1297

8. Mahler DA, Wire P, Horstman D, et al. Effectiveness of fluticasone propionate and salmeterol combination delivered via the discus device in the treatment of chronic obstructive pulmonary disease. Am J Respir Crit Care Med 2002;166:1084-91. http://dx.doi.org/10.1164/rccm.2112055

9. Calverley PM, Boonsawat W, Cseke Z, Peterson S, Olsson H. Maintenance therapy with budesonide and formoterol in chronic obstructive pulmonary disease. Eur Respir J 2003;22:912-19. http://dx.doi.org/10.1183/ 09031936.03 .00027003

10. Calverley P, Pauwels R, Vestbo J, et al. Combined salmeterol and fluticasone in the treatment of chronic obstructive pulmonary disease: a randomized controlled trial. Lancet 2003;361:449-56. http://dx.doi.org/10.1016/S01406736(03)12459-2

11. Szafranski W, Cukier A, Ramirez A, et al. Efficacy and safety of budesonide/formoterol in the management of chronic obstructive pulmonary disease. Eur Respir J 2003;21:74-81. http://dx.doi.org/10.1183/ 09031936.03 .00031402

12. Hanania NA, Darken $P$, Horstman $D$, et al. The efficacy and safety of fluticasone propionate $(250 \mu \mathrm{g}) / \mathrm{salmeterol}(50 \mu \mathrm{g})$ combined in the discus inhaler for the treatment of COPD. Chest 2003;124:834-43. http://dx.doi.org/10.1378/ chest.124.3.834

13. Calverley PMA, Anderson JA, Bartolome MA, et al. Salmeterol and fluticasone propionate and survival in chronic obstructive pulmonary disease. N Engl J Med 2007;356(8):775-89. http://dx.doi.org/10.1056/NEJMoa063070

14. Wedzicha JA, Calverley PMA, Seemungal TA, Hagan G, Ansari Z, Stockley RA for the INSPIRE Investigators. The prevention of chronic obstructive pulmonary disease exacerbations by salmeterol/fluticasone propionate or tiotropium bromide. Am J Respir Crit Care Med 2008;177:19-26. http://dx.doi.org/10.1164/rccm.200707-9730C

15. Kardos P, Wencker M, Glaab T, Vogelmeier C. Impact of salmeterol/fluticasone propionate versus salmeterol on exacerbations in severe chronic obstructive pulmonary disease. Am J Respir Crit Care Med 2007;175:144-9. http://dx.doi.org/10.1164/rccm.200602-2440C

16. Gartlehner G, Hansen RA, Carson SS, Lohr KN. Efficacy and safety of inhaled corticosteroids in patients with COPD: a systematic review and meta-analysis of health outcomes. Ann Fam Med 2006;4(3):253-62. http://dx.doi.org/ 10.1370/afm.517

17. Mapel DW, Nelson LS, Lydick E, Soriano J, Ulcickas Yood M, Davis KJ. Survival among COPD patients using fluticasone/salmeterol in combination versus other inhaled steroids and bronchodilators alone. COPD: J Chronic Obstructive Pulmonary Disease 2007;4:127-34. http://dx.doi.org/10.1080/ 15412550701341111

18. Deyo RA, Cherkin DC, Ciol MA. Adapting a clinical comorbidity index for use with ICD-9-CM administrative databases. J Clin Epidemiol 1992;45:613-19. http://dx.doi.org/10.1016/0895-4356(92)90133-8

19. Breslow NE, Day NE. Statistical Methods in Cancer Research, Volume I - The Analysis of Case-Control Studies. Chapter V: Classical Methods of Analysis of Matched Data. 1980. Lyon, France: IARC Scientific Publications, No. 32. International Agency for Research on Cancer.

20. Matthews R, Brill I. SAS programs to select controls for matched case-control studies. SAS User Group Proceedings \#30. 2005. Paper 152-30.

21. Koivula I, Sten M, Mãkelã PH. Risk factors for pneumonia in the elderly. Am J Med 1994;96(4):313-20. http://dx.doi.org/10.1016/0002-9343(94)90060-4

22. Almirall J, Bolibar I, Balanzo $\neg$ X, Gonzalez CA. Risk factors for communityacquired pneumonia in adults: a population-based case-control study. Eur Respir J 1999;13(2):349-55.

23. Ewig S, Torres A. Severe community-acquired pneumonia. Clin Chest Med 1999;20(3):575-87.

24. Farr BM, Woodhead MA, Macfarlane JT, Bartlett CL, McCraken JS, Wadsworth J, Miller DL. Risk factors for community-acquired pneumonia diagnosed by general practitioners in the community. Respir Med 2000;94(5):422-7. http://dx.doi.org/10.1053/rmed.1999.0743

25. Scannapieco FA, Bush RB, Paju S. Associations between periodontal disease and risk for nosocomial bacterial pneumonia and chronic obstructive pulmonary disease. A systematic review. Ann Periodontol 2003;8(1):54-69. http://dx.doi.org/10.1902/annals.2003.8.1.54

26. Medina-Ramãn M, Zanobetti A, Schwartz J. The effect of ozone and PM10 on hospital admissions for pneumonia and chronic obstructive pulmonary disease: a national multicity study. Am J Epidemiol 2006;163(6):579-88. http://dx.doi.org/10.1093/aje/kwj078

27. Ruiz M, Ewig S, Torres A, et al. Severe community-acquired pneumonia. Risk factors and follow-up epidemiology. Am J Respir Crit Care Med 1999;160:9239.

28. Almirall J, Gonzalez CA, Balanzo X, Bolibar I. Proportion of communityacquired pneumonia cases attributable to tobacco smoking. Chest 1999;116(2):375-9. http://dx.doi.org/10.1378/chest.116.2.375

29. Soriano JB, Visick GT, Muellerova H, Payvandi N, Hansell AL. Patterns of comorbidities in newly diagnosed COPD and asthma in primary care. Chest 2005;128(4):2099-107. http://dx.doi.org/10.1378/chest.128.4.2099

30. Benfield $T$, Lange $P$, Vestbo J. COPD stage and risk of hospitalization for infectious disease. Chest 2008;134:46-53. http://dx.doi.org/10.1378/chest.072933

31. Calverley PMA, Spencer S, Willits L, Burge PS, Jones PW. Withdrawal from treatment as an outcome in the ISOLDE study of COPD. Chest 2003;124:13506. http://dx.doi.org/10.1378/chest.124.4.1350

32. Ernst P, Gonzalez AV, Brassard P, Suissa S. Inhaled corticosteroid use in chronic obstructive pulmonary disease and the risk of hospitalization for pneumonia. Am J Respir Crit Care Med 2007;176:162-6. http://dx.doi.org/10.1164/rccm.200611-16300C

\section{Available online at http://www.theprj.org}

